\title{
Inter-Provincial Migration Intentions of Family Physicians in Canada: The Roles of Income and Community Characteristics
}

\section{Intentions de migration interprovinciale chez les médecins de famille au Canada : rôles du revenu et des caractéristiques locales}

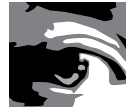 \\ HAIZHEN MOU, PHD \\ Associate Professor, Johnson-Shoyama Graduate School of Public Policy \\ University of Saskatchewan \\ Saskatoon, SK \\ M. ROSE OLFERT, MA \\ Professor, Johnson-Shoyama Graduate School of Public Policy \\ University of Saskatchewan \\ Saskatoon, SK
}

\begin{abstract}
The inter-provincial migration patterns of family physicians in Canada show that some provinces like Newfoundland and Saskatchewan experience persistent net out-migration, while others, including Ontario and British Columbia, are destinations more often than origins of migrants. Governments in provinces exhibiting net out-migration have responded with a number of incentive and recruitment programs. In this study, we investigate the determinants of the stated interprovincial migration intentions of 3,995 rural and urban family physicians in the 2010 wave of the National Physician Survey. We consider a range of physician characteristics, community attributes and working conditions. We find that in the intention to move, higher compensation has a modest effect, while the community characteristics have
\end{abstract}


a consistently important influence. Our results suggest that policy and program designers should acknowledge the critical role of community-level living and working conditions in their family physician recruitment and retention efforts.

\section{Résumé}

Les schémas de migration interprovinciale des médecins de famille au Canada montrent que certaines provinces comme Terre-Neuve et la Saskatchewan connaissent une émigration nette constante tandis que d'autres, notamment l'Ontario et la Colombie-Britannique, représentent plus souvent les points d'arrivée que les points de départ des migrants. Les gouvernements des provinces qui connaissent une émigration nette constante ont mis en place plusieurs mesures incitatives et programmes de recrutement pour faire face à la situation. Dans cette étude, nous examinons les déterminants des intentions de migration interprovinciale chez 3995 médecins de famille en milieux ruraux et urbains, et ce, dans le cadre du Sondage national des médecins de 2010. Nous avons pris compte de plusieurs caractéristiques des médecins et des communautés, ainsi que des conditions de travail. Nous avons observé qu'une plus grande rémunération a de modestes effets sur l'intention de déménager, alors que les caractéristiques de la communauté ont une influence assez importante. Nos résultats font voir que, dans leurs efforts pour recruter et retenir les médecins de famille, les responsables des politiques et des programmes devraient tenir compte des rôles importants liés au niveau de vie dans la communauté et aux conditions de travail.

\section{Introduction}

An oft-cited symptom of the consequences of the current geographic distribution of physicians in Canada is the increasing number of patients unable to find a family doctor and having to resort to emergency rooms and walk-in clinics for their primary care. In the past decade, a number of provincial governments have increased physicians' pay to attract them to their provinces (Grant and Hurley 2013). As a result, the average incomes of physicians have increased from three-and-a-half times the average Canadian worker's salary to nearly four-and-a-half times (Grant and Hurley 2013). Financial incentives in one province have implications for the healthcare costs of other provinces, resulting in a "race to the top" by the provinces (McDonald and Worswick 2012).

Nevertheless, these policies have not been adequate to offset family physicians' apparent location preferences, as reflected in the net migration patterns that continue to disproportionately favour some provinces over others. Interprovincial migration of family physicians resulted in Newfoundland, Prince Edward Island, Saskatchewan, Manitoba and Nova Scotia being "net loss" provinces in 2010, while Ontario, British Columbia and New Brunswick gained more doctors than they lost. Quebec and Alberta maintained a relative stable supply of physicians (CIHI 2011). 
Numerous studies have focused on the importance of remuneration in the recruitment and retention of physicians, but few have modelled physicians as active agents who weigh all the competing incentives and constraints (Grépin and Savedoff 2009). The objective of this paper is to model Canadian family physicians' inter-provincial migration intentions to provide empirical evidence regarding the extent to which remuneration and community characteristics influence their migration intentions. While the current location of the surveyed physicians is known, and we exploit this information in terms of identifying the physicians as residing in "urban" or "rural" locations, data on intended migration exist only for moves out of province. Thus, our analysis does not extend to within-province moves.

\section{Literature Review}

There are numerous studies of location choice of physicians in Canada and abroad (Hurley 1991; Kazanjian and Pagliccia 1996; McGuire 2000; Simoens and Hurst 2004; Wade et al. 2007), particularly for rural and remote areas (Chauhan et al. 2010; Dauphinee 2006; Florizone 1997; Goetz and Debertin 1996; Hancock et al. 2009; Hays et al. 2003; Mainous et al. 1994; Nestman 1998; Pope et al. 1998; Rourke et al. 2003; Williams et al. 2001). Our focus in this study, inter-provincial migration, is just one manifestation of physician movement.

The major variables of importance in physicians' inter-provincial migration decisions can be clustered into a number of categories. First, existing studies have recognized the importance of personal characteristics. Young, male and single physicians are more likely to move than their counterparts (Basu and Rajbhandary 2006; Vanasse et al. 2009). Physicians usually move to other provinces within the first five years of establishing a medical practice (CIHI 2007). French-speaking physicians are less likely to move, confirming an expected language barrier between Quebec and other provinces (Benarroch and Grant 2004). Immigrant physicians in rural communities are drawn to the large cities in Ontario (McDonald and Worswick 2012).

Second, considerations pertaining to professional practice are cited as the most important factor in the migration decisions of physicians. Dissatisfaction with professional life and professional relationships are good predictors of physicians' intentions to move to other provinces (Vanasse et al. 2009), and also the migration from rural to urban areas. For example, physicians located in rural communities are more likely to move than those in urban centres because of the lack of partners, locum relief, support from specialists and uninterrupted free time from work (Barer et al. 1999; CIHI 2007). Indeed, the most commonly cited reasons for leaving rural practices by family physicians are factors like burnout, excessive workload, excessive on-call duties and lack of time off for vacations or continuing medical education, rather than income (Mainous et al. 1994; Nestman 1998; Williams et al. 2001).

Third, family concerns have become increasingly important in inter-provincial migration decisions of physicians. Preferences of physician spouses are particularly important because of the growing prevalence of two-income earner families (Barer et al. 1999; Mathews et al. 2012). Indeed, migration of physicians is a family decision that depends on the education, 
age and other characteristics of the spouses (McDonald and Worswick 2012). Since the availability of employment opportunities for spouses and the presence of professional/social peer groups for all members of physician families are concentrated in communities with a larger population (Barer et al. 1999), it becomes increasingly challenging for small communities to attract and support physician-spouse pairs (Mathews et al. 2012; Vanasse et al. 2009).

Fourth, there is evidence, albeit mixed, concerning the importance of the level of compensation in inter-provincial migration decisions of physicians. Benarroch and Grant (2004) find that income differences between provinces have a significant and positive effect on physicians' decision to move. This finding is partially confirmed by Rajbhandary and Basu (2006) for physicians residing in Ontario and Saskatchewan, but not for those from other provinces. Dostie and Léger (2009) find that individuals with greater unobserved ability or desire to generate income are more likely to migrate to provinces where the returns are greater. On the other hand, income and financial incentives have been shown to be ineffective in the long-term retention of physicians in underserved areas (Anderson and Rosenberg 1990; Sempowski 2004). While some physicians were attracted by higher salaries in other provinces, others reported that income had limited influence on their migration decisions (Mathews et al. 2012).

Fifth, a few studies address the role of community characteristics in migration decisions of physicians. For example, Thommasen et al. (2000) find that the percentage of physicians in British Columbia who practiced in the same community for at least 10 years increased sharply for communities of more than 7,000. In another study, Thommasen and Thommasen (2001) find that long-term physician retention rates are lower in health regions with lower family physician-to-population ratios and lower specialist-to-family physician ratios. A case study by Cameron et al. (2010) reveals that four community attributes - appreciation, connection, active support and physical/recreational assets - are positively related to physician retention in four rural Alberta communities.

Most of the studies summarized above about inter-provincial migration of physicians were conducted either at the provincial level (Basu and Rajbhandary 2006; Benarroch and Grant 2004; CIHI 2007) or individual physician level (Barer et al. 1999; Mathews et al. 2012; Vanasse et al. 2009). The few that explicitly studied community characteristics are all about the retention of physicians in local communities instead of inter-provincial migrations. In summary, none of the work discussed above has empirically studied the role of community characteristics in inter-provincial migration of physicians, probably due to the absence of a data set with detailed information of both physicians and communities.

\section{Methods}

From the literature reviewed above, the most cited reasons for migration are professional practice and family concerns. Many of these factors, in turn, are highly dependent on the population size of the community, as the latter will determine the community-level presence of a highly educated professional peer group, other family physicians and specialists (and thus oncall imperatives); the number and types of jobs for family members; the number and quality 
of educational possibilities; the recreation possibilities; and the access to international airports (Chen and Stuart 2008; Scott 2009; Stabler and Olfert 2002). In addition to local population size, the distance from a rural community to the nearest urban centre will be important, as it represents the cost of accessing professional support, as well as the full range of employment and consumption goods and services in larger centres (Partridge et al. 2008).

In equation (1) below, the inter-provincial migration intentions of family physicians is modelled as a choice between remaining in the current province versus moving, as a function of the physician's personal characteristics, the community characteristics and relative income that will be earned:

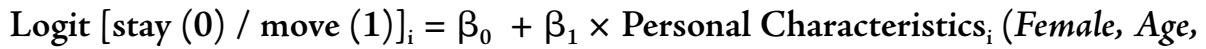 Age_Square, IMG, French) $+\beta_{2} \times$ Community Characteristics ir $_{\text {ir }}$ (Population, Distance) $+\beta_{3} \times$ Income Difference $_{\text {irj }}($ RealFeeDif $)+\varepsilon$}

where subscript $i$ represents the physician, $r$ his or her current community and $j$ the potential out-of-province destinations. The underlying assumption is that family physicians, like other professionals, make a choice regarding their practice location. This choice reflects their expectations regarding incomes, opportunities and/or lifestyle in potential future locations compared with their current situation (Beeson and Eberts 1989; Goetz and Debertin 1996). The logit estimation strategy reflects the dichotomous nature of the stay/move decision.

The migration intentions and personal information of physicians are from the 2010 wave of the National Physician Survey (NPS), the largest and most comprehensive census of family physicians in Canada, administered to all family physicians every three years. In total, 6,602 of 34,810 family physicians responded to the survey in 2010, a response rate of $19 \%$. We chose those respondents who are at or below the age of 65 in 2010 as our sample population because we want to understand inter-provincial migration intentions of family physicians for purposes other than retirement. We excluded the 19 family physicians practicing in the three territories because their communities are too different from the other communities, particularly in terms of distance to the nearest urban centre. After these selections, our targeted sample has 4,711 family physicians. Data availability for all the variables in equation (1) reduced our sample size to 3,995 , or $84.8 \%$ of the 4,711 physicians. In an examination of the mean values of variables in the full targeted sample and the reduced sample, we find virtually no difference in any of the variables of interest, leading us to infer that there is no bias due to missing values for some variables.

A Census Consolidated Subdivision (CCS) represents our "community" in which physicians serve the local and nearby clientele. We divide our sample into urban and rural communities, as the community characteristics are fundamentally different between the two, as are the recruitment and retention challenges. For purposes of this study, urban is defined as consisting of Census Metropolitan Areas (CMAs) and Census Agglomerations (CAs), as 
defined by Statistics Canada, while rural is everything else. According to Statistics Canada (2013), CMAs and CAs are geographic areas consisting of one or more neighbouring municipalities situated around a core. A CMA must have a total population of at least 100,000, of which 50,000 or more live in the core. A CA must have a core population of at least 10,000. In our sample, 3,348 physicians were practicing in urban communities and 647 in rural communities. The population size of communities is from Census 2006. The distance of a rural community from the nearest urban centre is provided by the Canada Rural Economy Research Lab at University of Saskatchewan (C-RERL). The distances were computed based on straight line calculations (i.e.," as the crow flies") by the Remote Graphics Software.

Because the NPS did not ask the family physicians who intend to move about their intended destinations, we make an assumption based on past trends. We assume the intended destinations are the top three most popular destination provinces of actual movers in 2010 (CIHI 2011), representing $80 \%$ of family physicians' moves within Canada. Our destination characteristic is the weighted average value for the three potential destination provinces, common for all family physicians in a province.

We use the difference in real fees for fee-for-service physicians between the current and destination provinces, RealFeeDif, to represent the higher real income in the current relative to potential destination provinces. Although only $41 \%$ of the family physicians in our sample work exclusively under the fee-for-service arrangement, the aggregate data show that $62 \%$ of all the clinical payments to family physicians were through fee-for-service in 2010 (CIHI 2012).

Although the response rate (19\%) for the NPS census is low, NPS (2010) reports strong similarity between subgroup distributions in the NPS respondents and in the physician population based on five basic group characteristics. The NPS study also acknowledges nonresponse bias in certain groups, including an over-representation of females and older family physicians. Another limitation is that there are no data of payment levels from alternative payment methods such as contract and salary.

The descriptions, data sources and descriptive statistics of all the variables, for the rural sample and urban sample separately, are provided in Table A1 of the Appendix. In the following section, we will first discuss the estimation results based on estimation equation (1) and then report results of several sensitivity analyses.

\section{Results}

Columns (1) and (2) in Table 1 present the estimation results for rural and urban physicians, respectively. Robust standard errors are used in all the estimations. A result is reported as statistically significant if its $p$-value is less than $5 \%$.

\section{Rural physicians}

For rural physicians (Col. 1), there is no statistically significant difference in the intention to move between female and male physicians, nor between younger and older physicians 
or between those who speak only French and others. However, results show that the odds of intending to move to other provinces for international medical graduates (IMGs) are three times those of Canadian medical graduates (CMGs), a finding consistent with that of Mathews et al. (2013) in Newfoundland.

TABLE 1. Migration intentions of rural and urban family physicians

\begin{tabular}{|c|c|c|c|c|c|c|}
\hline \multirow[t]{2}{*}{ Covariables } & \multicolumn{3}{|l|}{ Rural } & \multicolumn{3}{|l|}{ Urban } \\
\hline & Odds ratio & $95 \% \mathrm{Cl}$ & Z score & Odds ratio & $95 \% \mathrm{Cl}$ & Z score \\
\hline & \multicolumn{3}{|c|}{ Personal characteristics } & & & \\
\hline Female & 0.63 & {$[0.31-1.27]$} & -1.29 & $0.66 * *$ & {$[0.43-0.99]$} & -1.99 \\
\hline Age & 1.002 & {$[0.74-1.36]$} & 0.01 & $0.78 * * *$ & {$[0.65-0.93]$} & -2.82 \\
\hline Age_Square & 1.000 & {$[0.996-1.003]$} & -0.3 & $1.002 * *$ & {$[1.000-1.004]$} & 2.26 \\
\hline French & 0.14 & {$[0.02-1.07]$} & -1.89 & 0.32 & {$[0.1-1.06]$} & -1.86 \\
\hline \multirow[t]{2}{*}{ IMG } & $3.08 * * *$ & {$[1.54-6.14]$} & 3.19 & $2.93 * * *$ & {$[1.86-4.62]$} & 4.63 \\
\hline & \multicolumn{3}{|c|}{ Community characteristics } & & & \\
\hline Population & $0.96 * *$ & {$[0.93-1.00]$} & -2.01 & 1.000 & {$[0.999-1.000]$} & -1.26 \\
\hline \multirow[t]{2}{*}{ Distance } & 1.003 & {$[1.00-1.01]$} & 1.89 & & & \\
\hline & \multicolumn{3}{|c|}{ Income difference } & & & \\
\hline \multirow[t]{2}{*}{ Real Fee Dif } & 1.002 & {$[0.99-1.01]$} & 0.32 & 1.003 & {$[1.00-1.01]$} & 0.91 \\
\hline & \multicolumn{3}{|c|}{ Regression statistics } & & & \\
\hline N & 647 & & & 3,348 & & \\
\hline Pseudo $R^{2}$ & 0.12 & & & 0.07 & & \\
\hline Chi-square ( $p$-value) & $36.68(0.00)$ & & & $72.65(0.00)$ & & \\
\hline Linktest_hat & 0.03 & & & 0.59 & & \\
\hline Linktest_hatsq & 0.81 & & & 0.47 & & \\
\hline
\end{tabular}

Legend: $* p<0.1$; $* *$ p $<0.05 ; * * * * 0.01$.

In terms of community attributes, the estimation results show that population size of current rural community has a statistically significant influence on the inter-provincial migration intentions of family physicians. If Community A has 1,000 population less than Community B, the odds of a physician moving out is $4 \%$ higher. Neither distance to the nearest urban centre (Distance) nor differences in real fees between current and potential destination provinces (RealFeeDif) are influential at the 5\% statistical significance level.

\section{Urban physicians}

The results for urban physicians (Col. 2) differ markedly from those for rural physicians. Most personal characteristics of physicians are statistically significant, suggesting that gender, age and training background of physicians all affect migration intentions. In particular, the odds of moving for female physicians are only two-thirds those of male physicians. Like rural physicians, the odds of moving for IMGs are about three times those for CMGs. A one-year increase in the age of physicians decreases the odds of moving by $2.4 \%$. Further, the odds ratio 
of Age_Square, at 1.002, suggests that the speed of the influence of age on migration intentions, i.e., the slope of age, also diminishes with age. These findings about the influence of gender and age confirmed those of Basu and Rajbhandary (2006) and Vanasse et al. (2009).

Interestingly, population size of urban communities does not have a statistically significant effect on urban physicians' intention to move, maybe because the size of any urban centre (with a core population of at least 10,000) is sufficient for market size, sustainable working conditions and accessible amenities. Like rural physicians, the difference in real fees is not influential in migration intentions.

\section{The role of foreign training in migration intentions of rural physicians}

As $18 \%$ of the physicians practicing in rural communities are IMGs in our sample, we provide separate results for CMGs and IMGs who practice in rural communities in Columns 1 and 2 of Table 2 , respectively.

TABLE 2. Migration intentions of CMGs and IMGs in rural communities

\begin{tabular}{|c|c|c|c|c|c|c|}
\hline \multirow[t]{2}{*}{ Covariables } & \multicolumn{3}{|l|}{ Rural CMGs } & \multicolumn{3}{|l|}{ Rural IMGs } \\
\hline & Odds ratio & $95 \% \mathrm{Cl}$ & Z score & Odds ratio & $95 \% \mathrm{Cl}$ & Z score \\
\hline & \multicolumn{3}{|c|}{ Personal characteristics } & & & \\
\hline Female & 0.54 & {$[0.24-1.12]$} & -1.49 & 1.06 & {$[0.24-4.76]$} & 0.08 \\
\hline Age & 0.93 & {$[0.65-1.32]$} & -0.41 & 0.85 & {$[0.36-2.00]$} & -0.37 \\
\hline Age_Square & 1.0003 & {$[0.996-1.004]$} & 0.13 & 1.001 & {$[0.99-1.01]$} & 0.22 \\
\hline \multirow[t]{2}{*}{ French } & 0.18 & {$[0.02-1.46]$} & -1.61 & (dropped) & & \\
\hline & \multicolumn{3}{|c|}{ Community characteristics } & & & \\
\hline Population & $0.94 * *$ & {$[0.90-0.99]$} & -2.52 & 0.98 & {$[0.92-1.04]$} & -0.73 \\
\hline \multirow[t]{2}{*}{ Distance } & 1.001 & [0.997-1.005] & 0.56 & $1.01 * * *$ & {$[1.006-1.02]$} & 3.56 \\
\hline & \multicolumn{3}{|c|}{ Income difference } & & & \\
\hline \multirow[t]{2}{*}{ Real Fee Dif } & $0.99 *$ & {$[1.00-1.02]$} & -1.7 & $0.98^{* *}$ & {$[0.96-1.00]$} & 2.03 \\
\hline & \multicolumn{3}{|c|}{ Regression statistics } & & & \\
\hline N & 530 & & & 113 & & \\
\hline Pseudo $R^{2}$ & 0.09 & & & 0.28 & & \\
\hline Chi-square ( $p$-value) & $19.81(0.01)$ & & & $20.51(0.00)$ & & \\
\hline Linktest_hat & 0.61 & & & 0.001 & & \\
\hline Linktest_hatsq & 0.75 & & & 0.1 & & \\
\hline
\end{tabular}

Legend: ${ }^{*} p<0.1 ;$ *** $p<0.05$; ${ }^{*} * *_{p} p 0.01$. The variable "French" was automatically dropped by STATA because all the IMGs who speak only French do not plan to move in the next two years.

The sign and significance of all the coefficients in Column 1 (CMGs) are consistent with those in Column 1 of Table 1, suggesting that the results for all rural physicians are largely driven by physicians trained in Canada. In particular, CMGs value the working conditions implied by the community size. An increase of 10,000 population in a rural community reduces the odds of moving by $6 \%$ for CMGs. 
The motivations of IMGs in migration intentions (Col. 2) are quite different from those of CMGs. The community size has no statistically significant influence on IMGs' intention to move, while distance to the nearest urban centre (Distance) has a strong positive effect. The odds ratio associated with Distance suggests that 100 additional kilometres away from the nearest urban centre increases the odds of moving for IMGs by $12 \%$.

For IMGs (Col. 2), unlike CMGs, a higher real fee in the current province relative to potential destination province is associated with lower odds of moving (98\%). The odds ratio suggests that an additional $\$ 10,000$ higher real fee relative to the potential destination provinces will decrease their odds of moving by $2 \%$.

In contrast to rural physicians, there is no significant difference between IMGs and nonIMGs in terms of importance of income and community size for migration intentions among urban physicians (results available upon request).

\section{Sensitivity analysis}

The estimation models discussed above are all jointly significant at 5\% or lower level, as suggested by the log likelihood chi-square statistics and their associated $p$-values in Table 1 and Table 2. However, the low pseudo $R$-squares and some of the model specification error test statistics (Linktest results in Table 1 and 2) suggest that other factors should also be considered. We therefore conducted several sensitivity tests to see how the other, often suspected factors affect our main estimation results. The additional variables and their sources used in the sensitivity analyses are described in Table A1 in the Appendix.

First, physicians practicing in rural communities may not be paid through fee-for-service, but rather by salary or contract. We therefore estimate a model that includes alternative payment methods in addition to the variables in Table 2, on rural IMGs and rural CMGs separately. The findings concerning the relative importance of community attributes and fee difference for both IMGs and CMGs are robust to the inclusion of alternative payment methods (see Tables A2 and A3 in the Appendix).

Second, while overhead costs of running a clinic may be expected to affect physicians' migration intentions, regressions including overhead costs suggest that it is not a statistically significant factor for the migration intentions of either IMGs or CMGs in rural communities (see Tables A2 and A3 in the Appendix).

Third, some may wonder whether the location decisions of IMGs are somewhat constrained before they have their full licences. A condition of special provisional licences may be that IMGs sign a "return-for-service" agreement and serve in under-serviced communities for several years before obtaining a full licence (Mathews et al. 2013; Saskdocs 2015). This condition of provisional licences may reduce the mobility of IMGs in their first few years of practice. The maximum number of years allowed for IMGs with a provisional licence to obtain a full licence varies among provinces. For instance, three years are allowed in Newfoundland (Mathews et al. 2008, page 38), and five years in Manitoba (Armstrong et al. 2013 , page 8 ). We chose the maximum allowed time, five years, to represent the period during 
which the IMGs' location decisions may be encumbered because of not having a full licence. We therefore included a dummy variable indicating whether the years licenced to practice (provisional or full) are less than or equal to five years in a sensitivity analysis. The estimation result shows that whether an IMG has passed the maximum five-year period and (probably) achieved full licensure has no statistically significant effect on his or her migration intention (see Table A2 in the Appendix).

Finally, the results of multi-level (hierarchy) logit models confirmed that our estimation results in Table 2 are robust when the correlation among family physicians in the same community and in the same provinces are considered; our estimation results in Table 2 are also robust when family physicians are clustered by provinces (results available upon request).

\section{Discussion}

\section{Policy implications for all provinces}

Our results have common policy implications for rural and urban communities in all the provinces. First, it is harder for all communities to retain IMGs than CMGs, perhaps with implications for those provinces where international recruitment is a perceived solution in addressing the physician distribution problem (Dauphinee 2006; Mathews et al. 2013).

Second, further fee increases are not likely to be effective in retaining physicians. One possible explanation is that, as the threat of losing physicians is often used as a justification for fee increases in negotiations between physician unions and provincial governments (Grant and Hurley 2013), the existing fee rate structure across provinces likely already incorporates past incentives, making additional fee increases an ineffective instrument for influencing migration intentions of physicians.

\section{Policy implications for provinces with a net out-migration of family physicians}

During 2010, Newfoundland, Prince Edward Island, Saskatchewan, Manitoba and Nova Scotia suffered net losses of family physicians through inter-provincial migration of physicians (CIHI 2011). As rural physicians are much more likely to migrate than urban physicians, and the share of rural physicians in these "net loss" provinces (except for Prince Edward Island) are all above the national average, we next investigate the contribution of each of the statistically significant factors to rural physicians' intentions to move from these provinces. The total contributions are calculated as the product of the marginal effect associated with a factor in Table 2 and the difference in value of that factor between the top destination province and the current province. Columns $\mathrm{C} 1$ and $\mathrm{C} 2$ in Table 3 are about CMGs practicing in rural communities and Columns I1, I2 and I3 are about rural IMGs.

Column C2 suggests that the importance of population size varies across provinces for CMGs. For Newfoundland, if a rural community had an average population size as large as the average rural community in its top destination province, Alberta $(18,690$ instead of 5,650), the intention to move for CMGs would decrease by $3.1 \%$. Relative to the average 
moving intention of $37.5 \%$ in Newfoundland, this effect is minimal. On the other hand, for Nova Scotia, an average community size as small as that in Ontario will increase the migration intention of CMGs by $2 \%$, quite substantial relative to the overall migration intention of $4.2 \%$.

TABLE 3. Contribution of key factors to the migration intentions of rural physicians

\begin{tabular}{|l|l|l|l|l|l|l|}
\hline Column & (CI) & (C2) & (II) & (12) & (I3) \\
\hline Current province & $\begin{array}{l}\text { Top } \\
\text { destination } \\
\text { province }\end{array}$ & $\begin{array}{l}\text { Stay/Move } \\
\text { _MGs (\%) }\end{array}$ & $\begin{array}{l}\text { Contribution } \\
\text { of population } \\
(\%)\end{array}$ & $\begin{array}{l}\text { Stay/Move } \\
\text { IMGs (\%) }\end{array}$ & $\begin{array}{l}\text { Contribution } \\
\text { of distance (\%) }\end{array}$ & $\begin{array}{l}\text { Contribution of } \\
\text { RealFeeDif (\%) }\end{array}$ \\
\hline NL & AB & 37.5 & -3.1 & 58.3 & -6.7 & -17.5 \\
\hline NS & ON & 4.2 & 2.0 & 7.7 & -3.3 & 0.9 \\
\hline MB & ON & 11.4 & 0.8 & 21.4 & -6.3 & 6.3 \\
\hline SK & AB & 16.7 & -2.3 & 50 & -5.2 & -11.6 \\
\hline
\end{tabular}

This finding thus suggests that while improving the working conditions and quality of life in small rural communities will significantly reduce the out-migration of CMGs from Nova Scotia, such programs will be less effective in Newfoundland. Non-community factors, including probably the remote location of the province, play a more important role than population size in Newfoundland than in Nova Scotia.

A comparison between Column (I1) and Column (C1) shows that IMGs in all the "net loss" provinces are more likely to move than those trained in Canada. Column (I2) suggests the distance to the nearest urban centre is influential for the migration intentions of IMGs. For instance, IMGs practicing in rural Manitoba would be $6 \%$ less likely to move (to potentially Ontario), if their average travel distance to the nearest urban centre $(99 \mathrm{~km})$ were the same as in Ontario (46 km).

Column (I3) suggests that higher fees in the current province relative to the destination province have a substantial influence on the migration intention of rural IMGs. For example, if the real fee rate in Saskatchewan $(\$ 236,829)$ were to reach the same level as its top migration destination province Alberta $(\$ 291,948)$, the intention of moving for IMGs practicing in rural Saskatchewan would decrease by $11.6 \%$. Even relative to the globally high moving intention of IMGs in rural Saskatchewan (50\%), the influence of the fee difference is substantial.

\section{Conclusion}

This study investigates the extent to which remuneration and community characteristics influence the inter-provincial migration intentions of family physicians in Canada. Our findings suggest that the influence of higher compensation on inter-provincial migration intentions is rather modest. What competition through fee increases will accomplish is a cascading increase in healthcare costs in ALL provinces. The exception is IMGs practicing in rural communities, where higher fees play an important role in retaining IMGs in rural communities. As a policy 
option, this implies long-term high cost incentives to retain the IMGs in a community they would otherwise not choose.

Our results also suggest that the intention of migration for CMGs in rural communities is strongly influenced by population size of those communities. A larger population base increases the "market potential" for an individual physician and his or her spouse, the number of physicians present in the community as well as the total bundle of private and public goods and services that can be supported locally. While policy makers cannot change the size of rural communities, nor re-locate them, this is a very important result in terms of the realism, or cost, of trying to incentivize physicians to locate in small/rural communities where they would not otherwise choose to locate their practice. Doing so may be a very high-cost and short-term remedy. Where a decision is made to recruit to a small community, there may be some benefit to looking for ways to mimic urban conditions by way of spousal hire programs, assistance for conference travel and support for other means of accessing peers and specialists.

The findings regarding the importance of a minimum population size for retention of physicians may also suggest looking for a more flexible model of primary care delivery in rural communities. For example, by grouping physicians to work at an appropriately chosen centre for nearby rural communities via "Collaborative Emergency Centres" - a recent initiative of Nova Scotia and Saskatchewan - physicians can share workload and on-call responsibilities, provide professional support to each other and enjoy a higher satisfaction with work-life balance (Government of Saskatchewan 2014).

\section{Acknowledgements}

The study described in this paper was conducted utilizing original data from the National Physician Survey Database, part of the National Physician Survey project co-led by The College of Family Physicians of Canada, the Canadian Medical Association, and the Royal College of Physicians and Surgeons of Canada, and supported by the Canadian Institute for Health Information and Health Canada. The authors want to thank Artem Safarov, Jonas Eriksson, and Omotooke Odeniyi for their help with the data.

Correspondence may be directed to: Haizhen Mou, PhD, Associate Professor, Johnson-Shoyama Graduate School of Public Policy, University of Saskatchewan, 101 Diefenbaker Place, Saskatoon, SK, S7N 5B8; tel.: (306) 966-5305, fax: (306) 966-1967; e-mail: Haizhen.mou@usask.ca.

\section{References}

Armstrong, S., J. François, X.-M. Li and B. Seo. 2013. “Understanding Canadian and International Medical Graduate Physicians in Manitoba." Final Report for the Division of Continuing Professional Development, Faculty of Medicine, University of Manitoba.

Anderson, M. and M.W. Rosenberg. 1990. “Ontario’s Underserviced Area Program Revisited: An Indirect Analysis." Social Science and Medicine 30(1): 35-44.

Barer, M.L., L. Wood and D.G. Schneider. 1999. “Towards Improved Access to Medical Services for Relatively Underserved Populations: Canadian Approaches, Foreign Lessons." Vancouver: Centre for Health Services and Policy Research, The University of British Columbia. 
Basu, K. and S. Rajbhandary. 2006. “Interprovincial Migration of Physicians in Canada: What Are the Determinants?" Health Policy 76(2): 186-93.

Beeson, P.E. and R.W. Eberts. 1989.“Identifying Productivity and Amenity Effects in Interurban Wage Differentials". Review of Economics and Statistics 71(3): 52-43.

Benarroch, M. and H. Grant. 2004. “The Interprovincial Migration of Canadian Physicians: Does Income Matter?” Applied Economics 36(20): 2335-45.

Cameron, P.J., D.C. Este and C.A. Worthington. 2010.“Physician Retention in Rural Alberta: Key Community Factors." Canadian Journal Public Health 101(1): 79-82.

Chauhan, T.S., M. Jong and L. Buske. 2010.“Recruitment Trumps Retention: Results of the 2008/2009 CMA Rural Practice Survey." Canadian Journal of Rural Medicine 15(3): 101-07.

Chen, Y. and S.R. Stuart. 2008. "Local Amenities and Life-Cycle Migration: Do People Move for Jobs or Fun?" Journal of Urban Economics 64(3): 37-519.

CIHI (Canadian Institute of Health Information). 2012. “National Physician Database, 2010-2011”. Retrieved April 10, 2014. <https://secure.cihi.ca/estore/productSeries.htm?locale=en\&pc=PCC476>.

CIHI (Canadian Institute of Health Information). 2011. "Supply, Distribution and Migration of Canadian Physicians, 2010". Table 9.0: Family Medicine Physicians Migrating between Canadian Jurisdictions Who Were in Canada.

CIHI (Canadian Institute of Health Information). 2007. Distribution and Internal Migration of Canada's Physician Workforce. Ottawa: CIHI.

Dauphinee, D. 2006.“The Circle Game: Understanding Physician Migration Patterns within Canada." Academic Medicine 81(12 Suppl): S49-54.

Dostie, B. and P.T. Léger. 2009. “Self-Selection in Migration and Returns to Unobservables.” Journal of Population Economics 22(4): 1005-24.

Florizone, A. 1997. "SMA Survey of Rural Physicians." Canadian Journal of Rural Medicine 2(4): 180-86.

Goetz, S.J. and D.L. Debertin. 1996. “Rural-Urban Locational Choices of Medical Doctors: A County-Level Analysis." Review of Agricultural Economics 18(4): 547-63.

Government of Saskatchewan. 2014. "New Collaborative Emergency Centre Opens in Shaunavon". News release. Retrieved August 7, 2014. <www.gov.sk.ca/news?newsId=dd685461-78ec-4989-86b1-c96a325de58e >.

Grant, H.M. and J. Hurley. 2013. “Unhealthy Pressure: How Physician Pay Demands Put the Squeeze on Provincial Health-Care Budgets." SPP Research Papers. The School of Public Policy, University of Calgary 6(22).

Grépin, K.A. and W.D. Savedoff. 2014.“Editor's Choice: 10 Best Resources on ... Health Workers in Developing Countries." Health Policy and Planning 24(6): 479-82.

Hancock, C., A. Steinbach, T.S. Nesbitt, S.R. Adler and C.L. Auerswald. 2009.“"Why Doctors Choose Small Towns: A Developmental Model of Rural Physician Recruitment and Retention." Social Science E Medicine 69(9): $1368-76$.

Hays, R., S. Wynd, C. Veitch and L. Crossland. 2003. “Getting the Balance Right? GPs Who Chose to Stay in Rural Practice". Australian Journal of Rural Health 11(4): 193-98.

Hurley, J.E. 1991."Physicians' Choices of Specialty, Location, and Mode: A Reexamination within an Interdependent Decision Framework." The Journal of Human Resources 26(2): 47-71.

Kazanjian, A. and N. Pagliccia. 1996. "Key Factors in Physicians' Choice of Practice Location: Findings from a Survey of Practitioners and Their Spouses." Health and Place 2(1): 27-34.

Mainous, A.G., M. Ramsbottom-Lucier and E.C. Rich. 1994.“The Role of Clinical Workload and Satisfaction with Workload in Rural Primary Care Physician Retention." Archives of Family Medicine 3(9): 787-92.

Mathews, M., S.L. Heath, S.M. Neufeld and A. Samarasena. 2013. “Evaluation of Physician Return-for-Service Agreements in Newfoundland and Labrador." Healthcare Policy 8(3): 43-56. doi:10.12927/hcpol.2013.23209.

Mathews M, M. Seguin, N. Chowdhury and R. Card. 2012. “Generational Differences in Factors Influencing Physicians to Choose a Work Location." Rural And Remote Health [serial online]. 12: 1864. 


\section{Inter-Provincial Migration Intentions of Family Physicians in Canada}

Mathews, M., A.C. Edwards and J.T.B. Rourke. 2008. "Retention of Provisionally Licensed International Medical Graduates: A Historical Cohort Study of General and Family Physicians in Newfoundland and Labrador." Open Medicine 2(2): 37-44.

McDonald, J.T. and C. Worswick. 2012."The Migration Decisions of Physicians in Canada: The Roles of Immigrant Status and Spousal Characteristics." Social Science and Medicine 75(9): 1581-88.

McGuire, T.G. 2000. “Physician Agency." Chapter 9 in A.J. Culyer and J.P. Newhouse, ed. Handbook of Health Economics 1: 461-36. Amsterdam: Elsevier.

National Physician Survey (NPS). 2010. “2010 National Physician Survey Questionnaire Design”. <http://nationalphysiciansurvey.ca/wp-content/uploads/2012/05/2010-complete-methods-en.pdf>.

Nestman, N.A. 1998. "The Retention of Physicians in Rural Areas: The Case of Nova Scotia." Kingston: IRC Press Industrial Relations Centre, Queen's University. Retrieved April 10, 2014. <http://irc.queensu.ca/gallery/1/ cis-retention-of-physicians-in-rural-areas-the-case-of-nova-scotia.pdf $>$.

Partridge, M.D., D.S. Rickman, K. Ali, M.R. Olfert. 2008.“Employment Growth in the American Urban Hierarchy: Long Live Distance". Berkeley Journal of Macroeconomic-Contributions 8(1). <www.bepress.com/bejm/ vol8/iss1/art10>.

Pope, A.S.A., G. Grams, C.B.C. Whiteside and A. Kazanjian. 1998. "Retention of Rural Physicians: Tipping the Decision-Making Scales." Canadian Journal of Rural Medicine 3(4): 209-16.

Rajbhandary, S. and K. Basu. 2006. "Interprovincial Migration of Physicians in Canada: Where Are They Moving and Why?" Health Policy 79(2/3): 265-73.

Rourke J, F. Incitti, L. Rourke and M. Kennard. September 2003. “Keeping Family Physicians in Rural Practice. Solutions Favoured by Rural Physicians and Family Medicine Residents." Canadian Family Physician [serial online]. 49: 1142-49.

Saskdocs. 2015. “International Medical Graduate (IMG) Program - SIPPA”. < http://www.saskdocs.ca/work/ family-physician---imgs/sippa/>.

Scott, A.J. 2009."Human Capital Resources and Requirements across the Metropolitan Hierarchy of the USA". Journal of Economic Geography 9(2): 207-26.

Sempowski, I.P. 2004."Effectiveness of Financial Incentives in Exchange for Rural and Underserviced Area Returnof-Service Commitments: Systematic Review of the Literature." Canadian Journal of Rural Medicine 9(2): 82-88.

Simoens, S. and J. Hurst. 2004. "Matching Supply with Demand for the Services of Physicians and Nurses." Chapter 4 in Towards High-Performing Health Systems: Policy Studies. Paris: OECD.

Stabler, J.C. and M.R. Olfert. 2002. Saskatchewan's Communities in the 21st Century: from Places to Regions. Regina: Canadian Plains Research Centre.

Statistics Canada. 2013. "Census Metropolitan Area (CMA) and Census Agglomeration (CA)". <www.statcan. gc.ca/pub/92-195-x/2011001/geo/cma-rmr/cma-rmr-eng.htm>.

Thommasen, H., J. Berkowitz and S. Grzybowski. 2000. “Community Factors Associated with Long-Term Physician Retention." BC Medical Journal 42(9): 426-29.

Thommasen, H.V. and A.T. Thommasen. 2001. "General Practitioner-to-Population Ratios and Long-Term Family Physician Retention in British Columbias Health Regions." Canadian Journal of Rural Medicine 6(2): 115-22.

Vanasse, A.S.S., J. Courteau and M.G. Orzanco. 2009. “Canadian Family Physicians' Intentions to Migrate: Associated Factors." Canadian Family Physician 55(4): 396-97. e1-6.

Wade, M.E., J.J. Brokaw, T.W. Zollinger, J.S. Wilson, J.R. Springer, D.W. Deal et al. 2007.“Influence of Hometown on Family Practitioner's Choice to Practice in Rural Settings." Family Medicine 49(4): 246-52.

Williams, E.S., T.R. Konrad, W.E. Scheckler, D.E. Pathman, M. Linzer, J.E. McMurray et al. 2001.“Understanding Physicians' Intentions to Withdraw from Practice: The Role of Job Satisfaction, Job Stress, Mental and Physical Health." Health Care Management Review 26(1): 7-19. 